PEDAGOGISK FORSKNING I SVERIGE Vol 25 No 4 (2020) ISSN 1401-6788

\title{
Debatt
}

\section{Respekt för varandras kunskaper}

\author{
Elisabet Nihlfors, professor \\ Institutionen för pedagogik, didaktik och utbildningsstudier, Uppsala \\ universitet \\ Kontakt: elisabet.nihlfors@edu.uu.se
}

Pedagogisk forskning i Sverige ställde frågan, våren 2020, om ett nytt paradigm kring forskning och utbildning/skola är under framväxt. Koppling görs till praktiknära forskning och till växelspelet mellan pedagogik som en rigorös akademisk disciplin (vetenskaplig legitimitet) och möjligheten att samtidigt utgöra en relevant professionsbas (professionell legitimitet).

Redaktörerna har gett mig möjlighet att göra en avslutande reflektion. Efter att ha läst samtliga, intressanta och tankeväckande debattartiklar vill jag lyfta fram ett par områden av betydelse i sammanhanget; forskningens betydelse för kunskaps-och verksambetsutveckling och betydelsen av att professioner aktivt medverkar till sin egen kunskapstillväxt. I texten nedan lutar jag mig emot och tar även spjärn mot de olika artiklarna och hoppas därmed medverka till ett fortsatt samtal.

Artikeln utgår från föreställningen om att forskning är en verksamhet som syftar till att systematiskt generera kunskap. Forskning genomförs med beprövade vetenskapliga metoder, redogör öppet för hur resultaten genererats och publiceras efter vetenskaplig granskning (jfr Persson, 2020). Forskning bedrivs efter specifika vetenskapliga och etiska regler oavsett var den genomförs. Forskning leds av forskare, det vill säga disputerade personer som är anställda på ett lärosäte och/eller hos en skolhuvudman. Varför denna inledande distinktion?

Forskning och utveckling är varandras förutsättningar och lägger grunden för en högkvalitativ utbildning. Men obalansen i resurstillgång mellan korta (3-åriga), uppifrån styrda skolutvecklingsinsatser och mer långsiktiga, kritiskt 
granskande forskningsprojekt är oerhört stor. Att forskare är anställda både inom privat och offentlig sektor, hos skolhuvudman och på lärosäte är en självklarhet men ändå, kanske beroende på att alltför få lektorer har forskning i sin tjänst, behöver resursbehovet till forskning understrykas. Denna situation påverkar idag synen på forskning och forskare men även på vad praktiknära forskning kan innebära.

Redaktörerna konstaterar i sin inledningsartikel att praktiknära forskning inte är något nytt. Diskussioner har pågått och pågår både om benämning och definition; om det ska heta praktiknära-, praxisutvecklande, praktikutvecklande eller kanske uppdragsrelevant forskning och hur den ska definieras (VR, 2003; VR, 2005; SOU 2018:19; Serder \& Malmström, 2020; Nilholm, 2020). Diskussionerna rör ett omfattande forskningsområde, i behov av olika teorier och forskningsdesign. Att diskussionen pågår beror också på bristen på forskningsmedel inom det utbildningsvetenskapliga fältet vilket skapar behov av att rubricera forskningsmedel för att till exempel garantera en infrastruktur för samverkan som stärker den vetenskapliga grunden $i$ lärarutbildningarna och $i$ skolan (Utbildningsdepartementet, 2017). Så uttrycks uppdraget till försöksverksamheten ULF. Det som utmärker forskning som finansieras av ULF-medel är att den är kollaborativ (Eriksson, 2018) och har en syn på olika aktörers yrkeskunskap som är symmetrisk och komplementär.

Redan för 20 år sedan när utbildningsvetenskaper ${ }^{1}$ etablerades diskuterades behovet av praktiknära forskning inklusive forskning i och för lärarutbildningarna. Sen dess ha skollagen kompletterats så att all undervisning, såväl på lärosätena som hos skolhuvudmännen, ska vila på vetenskaplig grund och beprövad erfarenhet. Men fortfarande saknas tillräckliga forskningsresurser; antalet lärarutbildningsplatser står inte i paritet till forskningsmedlen, disputerade lärare saknar forskningstid vilket $\mathrm{i}$ sin tur innebär att studenterna inte alltid möter levande forskande miljöer under sin utbildning (Prop. 2016/17:50).

Försöksverksambeten ULF, som omnämns i flera av artiklarna, syftar till att lägga grunden för en nationell infrastruktur, genom ett nationellt ULF-avtal med regionala och lokala tillämpningar. Ett sätt att garantera långsiktighet och nationell likvärdighet $\mathrm{i}$ kunskapsproduktionen i såväl lärarutbildningarna som utbildningen från förskola till vuxenutbildning.

Lärares förmåga att kritiskt undersöka och granska sin egen verksamhet grundläggs i lärarutbildningen men behöver underhållas och utmanas i forsknings- och utvecklingsmiljöer. Ett första steg i att skapa en infrastruktur är därför att etablera miljöer där regelbundna samtal kan ske, där kunskapsbehov kan möta befintliga forskningsresultat som kan prövas och utvärderas. Miljöer där både lärarstuderande, lärare, handledare och forskare kan delta och där det sker ett ömsesidigt utbyte som syftar till att utveckla såväl forsknings- som praktiklitteracitet. 
Några av dessa miljöer kan utvecklas till ett tredje rum (Prøitz, 2020; Olsson \& Brunner Cederlund, 2020). Mötesplatser som bygger på ömsesidig respekt, där en ökad förståelse för varandras och andras kunskaper lägger grunden också för kritisk granskning (Blossing, 2020). Forskning som söker ny kunskap ställer krav på öppenhet för det oväntade, för resultat som kan utmana det befintliga (Wedin, 2020). Detta tredje rum kan vara en plats där befintlig kunskap diskuteras och används för att utveckla kvaliteten i undervisningen men också för att initiera nya forskningsprojekt. "The goal is to understand a problem or an issue that is too complex for any party to study alone" (Van de Ven, 2013, s. 289).

Om investeringar görs $\mathrm{i}$ de professionellas egen kunskapsproduktion, bland annat $\mathrm{i}$ och genom ett ULF-avtal, finns förutsättningar för mer långsiktiga lösningar, ökad kritisk granskning och en högre kvalitet i verksamheterna (von Greiff, 2020). Här kan även förenade tjänster mellan lärosäte och skolhuvudman vara en annan viktig förutsättning för att möjliggöra att rätt kompetens finns där den behövs, när den behövs genom hela forskningsprocessen (se Van de Ven, 2013, s. 267). Ett sådant synsätt ökar även behovet av samverkan mellan lärosäten med lärarutbildning, mellan skolhuvudmännen och naturligtvis mellan lärosäten och skolhuvudmän. Det finns kluster, noder och olika typer av samverkan men med ett UFL-avtal kan strukturen behöva ses över och nya etableras. Att utveckla och vårda forskningssamverkan kostar både tid och pengar utöver uthållighet, lyhördhet, kreativitet och mod (Hermansson \& Ahnborg, 2020).

Det paradigmskifte som pågår handlar kanske om respekt för forskares arbete utifrån redovisade resultat och inte utifrån var forskaren är anställd. Ömsesidig respekt för varandras olika kunskaper som i samverkan kan skapa ny kunskap. Det handlar om att ha tillit till att de professionella på lärosäten och hos skolhuvudmän, i genuin samverkan, tar fram kunskap, med både hög kvalitet och relevans (Jarl \& Taube, 2020) för att på sikt nå bättre resultat då "engaged scholarship can produce knowledge that is more penetrating and insightful than when scholars or practioners work on the problems alone" (Van de Ven, 2013, s. 265).

\section{NOTER}

${ }^{1}$ Inom utbildningsvetenskap studeras lärande, didaktik och ämnesdidaktik, undervisning, sociala och kulturella aspekter på utbildning, utbildningspolitik, utbildningssystem och organisation samt profession, och speciellt med relevans för skolans och förskolans utveckling. Forskningen bedrivs inom flera olika vetenskapliga discipliner och bidrar till kunskapsutveckling och förstärker den vetenskapliga grunden för utbildning (www.vr.se, 2020-11-30). 


\section{REFERENSER}

Blossing, Ulf (2020). Samverkansprocessens problematik i den praktiknära forskningen. Pedagogisk Forskning i Sverige. Ahead of print. https://pedagogiskforskning.se/debatt-2020-praktiknara-forskning/

Eriksson, Inger (2018). Lärares medverkan i praktiknära forskning: Förutsättningar och hinder. Utbildning och lärande, 12(1), 27-40.

Hermansson, Karin, \& Ahnborg, Marie-Hélène (2020). Praktiknära forskning i samverkan - hur ska det gå till? Pedagogisk forskning i Sverige, Ahead of print. https://pedagogiskforskning.se/debatt-2020-praktiknara-forskning

Jarl, Maria, \& Taube, Magdalena (2020). Organiserade partnerskap i lärarutbildning lägger grunden för praktiknära forskning. Pedagogisk forskning i Sverige, Ahead of print. https://pedagogiskforskning.se/debatt-2020-praktiknara-forskning

Nilholm, Claes (2020). Praktiknära eller uppdragsrelevant forskning? Pedagogisk forskning i Sverige, 25(2-3), 157-159. DOI: 10.15626/pfs25.0203.09

Olsson, Lars, \& Brunner Cederlund, Anna (2020). Det tredje rummet som mötesplats. Pedagogisk forskning i Sverige, Ahead of print. https://pedagogiskforskning.se/debatt-2020-praktiknara-forskning.

Persson, Anders (2020). Dubbel närhet och distans behövs i praktiknära forskning. Pedagogisk Forskning i Sverige, 25(2-3), 149-152. DOI: $10.15626 / p f s 25.0203 .07$

Prop. 2016/17:50. Kunskap i samverkan - för sambällets utmaningar och stärkt konkurrenskraft. Stockholm: Utbildningsdepartementet.

Prøitz, Tine S. (2020). Praksisnær forskning og partnerskap i et tredje rom. Pedagogisk. forskning i Sverige, Ahead of print. https://pedagogiskforskning.se/debatt2020-praktiknara-forskning

Serder, Margareta, \& Malmström, Martin (2020). Vad talar vi om när vi talar om praktiknära forskning? Pedagogisk forskning i Sverige, 25(1), 107-109. DOI: $10.15626 / \mathrm{pfs} 25.01 .07$

SOU 2018:19. Forska tillsammans - samverkan för lärande och förbättring. Stockholm: Utbildningsdepartementet.

Utbildningsdepartementet (2017). Regeringsbeslut. Uppdrag om försöksverksamhet med praktiknära forskning. U2015/03573/UH, U2017/01129/UH. Stockholm: Utbildningsdepartementet.

https://www.regeringen.se/49ba4e/contentassets/ed0440fcafde445ca40cb470c3e e d7fc/uppdrag-om-forsoksverksamhet-med-praktiknara-forskning.pdf [Hämtad 2020-11-30]

Van de Ven, Andrew H. (2013). Engaged Scholarship. A guide for organizational and social research. Oxford: Oxford University Press. 
VR (2003). Forskning av denna världen I - praxisnära forskning inom utbildningsvetenskap. Stockholm: Vetenskapsrådets rapportserie.

VR (2005). Forskning av denna världen II - Om teorins roll i praxisnära forskning. Stockholm: Vetenskapsrådets rapportserie.

von Greiff, Camilo (2020), Praktiknära forskning - ett område med vind i ryggen. Pedagogisk forskning i Sverige, 25(2-3), 153-156. DOI: 10.15626/pfs25.0203.08

Wedin, Åsa (2020). Att hantera mindre goda exempel - dilemma för praktiknära forskning. Pedagogisk Forskning i Sverige, 25(1), 102-105. DOI: $10.15626 / \mathrm{pfs} 25.01 .06$ 